\title{
"Memories Warm You Up from the Inside. But They also Tear You Apart": Editorial for the Special Issue on Memory Training for Emotional Disorders
}

\author{
E. S. Becker ${ }^{1}$ - M.-A. Vanderhasselt ${ }^{2}$ - E. H. W. Koster ${ }^{2}$ J. N. Vrijsen ${ }^{3,4}$
}

Published online: 13 July 2021

(c) The Author(s), under exclusive licence to Springer Science+Business Media, LLC, part of Springer Nature 2021

\section{Why Memory?}

\section{Personal Motivation: In Memoriam Gordon Bower}

Memory has been my (Eni Becker's) first scientific interest (Becker et al., 1994), and it has kept its fascination for me. Our memory is in a way our essence, defines and shapes us. I find the idea fascinating that memory is our past, and as thus is stable and reliable, while actually memory is quite changeable, elusive even, and thus our past is changing all the time. From the beginning I was interested in how memory might impact mental health and psychopathology. Gordon Bower's theory on mood and memory $(1981,1987)$ was my scientific starting point (and I was very lucky to have him as a sparring partner, thank you Gordon), as it has been for many others. How do emotion and information processing interact, and what if there is more than an "emotion" if there is an emotional disorder, a prolonged dysfunctional state?

\section{Professional Motivation}

We as guest editors of this special issue share many things such as being behavioral scientists and psychologists, living in the BeNeLux in Europe, and having a great sense of humor. We also share, as Eni already denotes above, a

\section{J. N. Vrijsen}

Janna.Vrijsen@radboudumc.nl

1 Behavioural Science Institute, Radboud University Nijmegen, Nijmegen, The Netherlands

2 Department of Experimental Clinical and Health Psychology, Ghent University, Ghent, Belgium

3 Department of Psychiatry, Donders Institute for Brain, Cognition and Behaviour, Radboud University Medical Centre, Nijmegen, The Netherlands

4 Pro Persona Mental Health Care, Depression Expertise Center, Nijmegen, The Netherlands fascination for memory. Why? Because memory is essential for us as human beings. It is essential because it is such a big part of our sense of 'self'. In fact, philosopher John Locke believed that a continuity of consciousness and memory establishes the 'self' over time.

Early experiences shape our brain including the way information is stored and the memories that follow from that. New information is always processed in the light of existing information networks, or, memories. As the quote used in the title of this editorial states: "Memories Warm You Up from the Inside. But They also Tear You Apart". They drive what we do and how we feel, both contributing to adaptive healthy behavior and optimism but also resulting in sadness, fear and destructive behavior. So memory is essential for us as human beings because it shapes our personality and our actions, it is the basis for learning and it is therefore logical to look at alterations in memory function to explain psychopathology. And this also means that influencing and changing memory processes is probably essential for therapy success. Memory is seen as crucial for us as human beings, for our personality and our development, and the links to dysfunctional behavior are obvious. It is however only relatively recently that these issues have been considered by contemporary theorists, and significant gaps remain in our knowledge. Even more strikingly, at the moment, memory does not play a significant role in psychotherapy, meaning that very few interventions seem to target memory processes directly and explicitly. This gap was the motivation and starting point for this special issue on 'Memory training for emotional disorders'.

\section{Memory Systems}

When we think of memory, most of us think of personal memories: Warming reminiscence of the past or painful memories of trauma, failure and shame. But the memory system is very 
complex, and it has a central role in information processing that goes way beyond our personal memories. It can be divided into three functional systems: The sensory register (that is closely linked to attention and will not be part of this special issue), working memory, and long-term-memory.

Long-term-memory encompasses our storage of knowledge, procedural as well as episodic. Episodic long-term memory contains what we generally refer to when we talk about 'memories'. We can bring previous episodes to conscious awareness, say the Christmas morning when we were 8 years old and finally got the remote control car we wanted so badly. The episodic long term memory contains our autobiographical memory as well as the semantic memory, the latter being our more abstract knowledge of the world. And procedural long-term memory is where we keep information necessary for daily function, for example the knowledge needed to drive a car. On a neural basis long-termmemory is organized in three brain systems that acquire information simultaneously and in parallel (McDonald et al., 2004). The central structures of these three memory systems are the hippocampus, responsible for the storage of episodic memory, the amygdala for emotional memory, and the dorsal striatum for habit forming. These brain systems are all part of long-term-memory but do not really map with the theoretical entities of episodic and procedural memory. Although they process information independently, the systems can interact cooperatively or competitively. They all are linked to circuits in the prefrontal cortex that are related to mental control, and working memory processes, thus, connecting working memory and long-term memory. Working memory is our "mental workspace", it defines how well we can keep up goal directed behavior, concentrate, solve problems, but it is also our "gate-way" to long-term storage (what will be stored) or the entrance way of our memories (what will be remembered). It is very closely linked to executive control, and top-down regulation of emotional processes.

Episodic memory has been one of the first processes linked to psychopathology, partly because traumatic memories already played an important part in Freud's theory of psychopathology (1916/1917). But even more so when it became obvious that episodic memories are in part 'constructed memories', influenced by information networks called 'schemata'. The term was coined by Bartlett (1932), who thought that people have general ideas, schemas, about how things work and that these ideas organize and construct their memories. Schemas are efficient and structure our knowledge and experiences, but might also distort them, making them fit with our preexisting assumptions and experiences. This idea was taken up in Beck's seminal cognitive theory of depression (Beck, 1963, 1964). But although schemata and automatic thoughts were at the very center of this theory, and changing them is the goal of cognitive therapy; memory processes were actually not detailed in this theory. This more theoretical and fundamental approach was taken by Bower's network theory (1981). But then this theory was not related to psychopathology. Thus, Beck's theory more or less ignored the cognitive basics and Bower in turn did ignore the clinical aspects. Luckily, both theories spawned research into memory processes in psychopathology. But it took a long time until these findings and theories were translated into interventions.

\section{Long-Term Memory and Emotional Disorders}

There are some rather robust findings describing a central role for memory processes in emotional disorders. There is good evidence for a selective memory bias in depression, depressed participants showing 'mood-congruent' memory bias, meaning that negative episodic and/or autobiographical information gets recalled more efficiently and frequently (Matt et al., 1992), although studies in youth have more mixed results (Platt et al., 2017). A study of daughters of depressed mothers tentatively supports a cognitive-vulnerability model of memory bias in youth (Asarnow et al., 2014). The model proposed that biological (i.e. genetic) predisposition with early learning experiences result in the formation of depressotypic cognitive schemata, which when activated would result in negative memory biases. Indeed, the authors found that girls at familial risk of depression recalled fewer positive words compared to girls without this familial load. Anxiety also seems to be related to a better recall of threat-related items (Coles \& Heimberg, 2002; Mitte, 2008). Mood-congruent recall and reduced accessibility of moodincongruent material may increase emotion regulation difficulties (Joormann \& Stanton, 2016) and is associated with attention and interpretation biases (Everaert et al., 2014), and this way might enhance emotional problems.

Another robust finding is overgeneral (autobiographical) memory in psychopathology; autobiographical memory representing the intersection between memory, self, and social processes. A review (Williams et al., 2007) suggested that individuals with depression and post-traumatic stress disorder (PTSD), but also other psychological disorders, retrieve overgeneral memories when attempting to retrieve memories of specific events. The authors conclude that the overgeneralization seems to stem from traumata and can have effects on the retrieval of events that have nothing to do with the trauma itself. The effects of this overgeneralization of memory are rather severe: It is affecting a person's problemsolving ability and is a prediction of the course of disorders, being associated with poorer outcome in depression, PTSD, and a number of other conditions. It also diminishes coping not only in face of serious threat but also in everyday life, such as the birth of a child (Mackinger et al., 2000), and can hamper the therapeutic process. 


\section{Working Memory and Emotional Disorders}

These were all examples of the role of long-term-memory processes and psychopathology, but there is also working memory (WM). Working memory is a limited capacity store for retaining information for a brief period while performing mental operations on that information. In that sense, one can think of WM as a room with a certain volume through which perception is linked to long-term memory, by processing information and throwing certain information out the window. Working memory is thus more than short-term memory, because it is also the "place" where long-term memories are being manipulated or brought back to life, after which they are possibly stored again (reconsolidation). WM is responsible for, among other things, directing attention to relevant information, or suppressing irrelevant information, and therefore is tantamount for multi-tasking, and goal directed behavior. Stress and working memory are quite clearly linked, and not surprisingly early childhood stress is associated with impaired working memory, in clinical as well as healthy samples (Goodman et al., 2019). Impaired WM means compromised cognitive control, diminishing goal-directed behavior, decision making or emotion regulation. There are some specific theories looking at WM and emotional disorders (e.g. Hertel, 1997; Isen, 1984; Joormann, 2005; Linville, 1996). A review (Zetsche et al., 2018) showed a possible association of working memory and repetitive negative thinking (RNT) that does contribute to the development of depression and GAD. Individuals with high levels of RNT have the specific difficulty in discarding no longer relevant material from working memory-more specifically they have trouble with appropriately removing negative cognitions and memories that were activated by negative mood from working memory. These findings support current theories on the mechanisms underlying rumination, such as the impaired disengagement hypothesis by Koster et al. (2011). In adults with a chronic diagnosis of Anorexia Nervosa, the obsessive-compulsive rumination tendencies are supposed to be supported by excessive and rigid WM performance (Brooks et al., 2017). Thus, working memory function plays a crucial role in many different disorders, certainly for their maintenance but probably also for their development.

\section{Memory as Treatment Target: Mechanistic Approaches}

Albeit memory-be it long-term or working memory-is a huge determining part of our personality and plays an essential role in psychopathology, it has not been frequently directly targeted in treatment. One reason for this might be that memory for a long time was seen as a repository for our past, stable and truthful, and thus not something that can be targeted directly and modified. This view changed in part because of a treatment targeting memories, the 'recovered memory treatment' (Stocks, 1998). This treatment was aimed at helping persons to recover memories of childhood abuse often by means of hypnosis and hypnotic age regression, with the intention of then treating the fallout of the trauma. But the recovered memories were not always true: In 1997 a woman sued her psychiatrist and their hospital for inducing false memories, that led her to believe she had been a priestess in a satanic cult. She won the lawsuit and got more than 10 million dollars to recompense her. The societal and especially the personal costs of the falsely recovered memory, but also doubts about truthful memories about abuse, were (and still are) enormous. To better understand those phenomena, intensive research was conducted. One of the foremost scientists in the field is Loftus, who was building on research in the mid-1970s, where theorists increasingly stressed the reconstructive nature of memory. She showed that it is possible to plant false memories (Loftus, 1997; Loftus \& Bernstein, 2005). Creating false memories is a major threat but that memory is changeable can also be seen as a chance: We can 'change' our past, and thus, change the present and possibly the future. This discovery finally led to treatments that target memories directly.

Not surprisingly, the effort to develop interventions targeting memory processes has primarily been on PTSD. On the one hand PTSD is clearly linked to changes in cognitive processes including memory (Brewin, 2001; Ehlers et al., 2004), and on the other hand the idea to change the past is especially attractive in this disorder. A paper by Phelps and Hofmann (2019) starts, "If you could erase the worst day of your life, would you do it?". At the moment interventions integrating memory-editing are being investigated. This editing might be possible at initial storage, or consolidation or re-storage after retrieval, or reconsolidation. In all of those approaches single memories are usually targeted, like a trauma, or a fear-learning experience. An example for targeting consolidation is the usage of drugs, like propranolol, to interfere with the storage of the trauma. So far the results are rather mixed. There are also limits for the practical application because most of the time no therapist is there while a memory of a trauma is formed, while the actual trauma is taking place. An alternative approach is strengthening more 'safe'/positive memories to support extinction learning (Quirk et al., 2010) or to 'targeted memory reactivation' (TMR), that aims at altering the reactivation of memories to influence the strength of consolidation (Schouten et al., 2017), but admittedly these treatments are all still in the developmental stage. 
Targeting reconsolidation is in a way more promising, since this means altering an already existing memory. Reconsolidation provides a mechanism that may facilitate the 'constructive' nature of memory, by allowing the memory to be updated with additional information that is provided at the time of retrieval. Although we can modify memories that way, clinical applications (Morina et al., 2017) have not been studied much so far, or have not been overly successful. Mostly we have some promising (Brunet et al., 2008; Kindt \& van Emmerik, 2016), but also diverse studies on the matter (Wood et al., 2015, for an overview see, Elsey \& Kindt, 2017).

Another group of interventions is targeting memory with the help of computerized training programs that aim to directly target memory processes. These training types can be aimed at working memory or long-term-memory processes. To target working memory, tasks such as the Paced Auditory Serial Addition Test (PASAT; Siegle et al., 2007) or the N-Back (Jaeggi et al., 2008) are used to e.g. train depressed patients' cognitive capacities through down regulating emotional responses, with an ultimate aim to relieve emotional symptoms (Koster et al., 2017). To illustrate, Siegle et al. (2007) showed that the dorsolateral prefrontal cortex was engaged during the PASAT, in turn activating the cognitive control network, reducing ruminative tendencies and hence depressive symptoms.

There is admittedly an ongoing scientific dispute if working memory capacity and functioning, or cognitive control, can be modified at all (Shipstead et al., 2012; Simons et al., 2016), but here is a body of research indicating that intensive training can have reliable effects on cognitive performance on related tasks at behavioral and neural levels (see Au et al., 2015; Klingberg, 2010). Even more importantly working memory training can affect psychopathology. This has been best researched in depression where a PASAT-based cognitive control training is a promising intervention reducing rumination and depressive symptoms, usually in studies where the training was provided alongside treatment as usual (Koster et al., 2017). Moreover, an increase in working memory via neuromodulation of the prefrontal cortex (using transcranial Direct Current Stimulation (tDCS)) has been found to reduce momentary ruminative thinking in healthy volunteers (Vanderhasselt et al., 2013), showing that working memory is a causal mechanism underlying rumination.

There are fewer studies targeting long-term-memory processes and emotional memories, with the help of so-called cognitive bias-modification programs, or CBM-Memory. CBM-Memory is based on the notion that repeated retrieval of positive information can counter the dysfunctional and unhealthy ruminative thinking habit seen in depression vulnerable individuals. When approaching it from a schema or network perspective (cf. Beck's and Bower's theories), CBM-Memory strengthens positive information structures in the brain and thereby offers competition to the negative schemas or networks responsible for depression. In CBMMemory, individuals are repeatedly prompted to retrieve positive information (either learned words or autobiographical events) from memory (Hertel et al., 2017; Visser et al., 2020; Vrijsen et al., 2016, 2019). The emotional memory training is provided via a computer or smartphone, the latter to optimize transfer to daily life. CBM-Memory is still in its infancy, but may be promising as a future treatment add-on or aftercare eHealth/mHealth tool.

\section{Memory as Treatment Target: More Conventional Treatment Approaches}

There are also more conventional therapy approaches, such as imagery rescripting (ImRs), competitive memory training (COMET), or schema-therapy. Imagery rescripting tries to modify the content of preexisting unpleasant memories into more benign images or to use new positive images to rescript negative schematic beliefs (Holmes et al., 2007). Usually the negative, or traumatic memories are being brought up, and are then changed with the help of vivid imagery. It is possible (and assumed) that this also targets the memory reconsolidation process, but this has not been studied yet. A meta-analysis (Morina et al., 2017) concludes that ImRs can significantly reduce psychological complaints among individuals with different mental disorders. Most clinical trials have been in PTSD and in Social anxiety disorders. We do have evidence of the clinical use of this intervention, but studies showing that memories were really changed are scarce to non-existing, and we therefore cannot be sure of the mechanisms involved.

Both COMET and Schema therapy target maladaptive cognitive emotional networks underlying psychological problems. COMET was developed by Korrelboom and colleagues (Korrelboom et al., 2009) and is a transdiagnostic imagery training protocol aiming to teach how to feel (experientially) what is already known (intellectually), and to use imagery to enhance positive self-esteem. Schema-therapy was developed by Young et al. (2003). It follows a much more general approach and has at its center the modification of early maladaptive schemata. These are acquired in childhood, when basic needs of the child are not met. These schemata are supposedly memory-based and are the reason for dysfunctional behavior, or suboptimal coping strategies. Not the behavior but rather the schemata are targeted in schema-therapy. In a way both treatment approaches build on Beck's theory of maladaptive schemata, but research providing proof for the exitance or malleability of schemata is more or less non-existent. Even though the treatments show promise in helping patients, as of now, we have hardly any 
proof for their theoretical basis or the supposed mechanisms of change.

\section{Innovation and Integration}

What becomes clear from the overview provided here is that although memory is essential for us as human beings (and hey, also for other animals for that matter), and our actions and emotions, interventions targeting memory processes are underrepresented in clinical psychological research. Especially in comparison to work on for example attention. Specifically, the mechanistic approach to memory training often lacks evidence for clinical relevance and conversely, the mechanisms of change of the more conventional therapeutic approaches are not well understood. So there are well-studied interventions out there, without current clinical application and clinical approaches with little scientific evaluation of what happens during treatment. Moreover, the different memory training approaches are currently not integrated.

In this light it is important to note that few studies in younger (children, adolescents) individuals have been conducted. Besides the lack of a body of evidence of memory training in younger samples, the understanding of the relation between memory and psychopathology in younger individuals is currently limited. This is a shame, because it can inform about the etiology of emotional disorders.

A fairly recent research development is implementing (neuro)biological strategies to modify memory processing and content. This area of research is not covered in the current special issue because other outlets focus on (neuro)biology more. In the light of this special issue, it is good to note that there are many innovative research initiatives directed at augmentation (or interference) of memory processing and memory training effects. This through for example the administration of propranolol or transcranial Direct Current Stimulation (tDCS), the application of Eye Movement Desensitization and Reprocessing (EMDR) or other forms of working memory load, and even initiatives to change memory through sleep and physical activity/exercise.

In this special issue we present innovative work on memory training for (or: in the context of) emotional disorders, by combining treatment outcome studies with experimental work. This special issue starts with a review (Samide et al.) of the available literature regarding the role of memory processes in the field of emotion regulation. Subsequently, this review consists of scientific studies on conventional treatment and mechanistic approaches. As such, the effects of cued retrieval training of autobiographical information in students (Hertel et al.) are presented. The protocol of an imagery rescripting and memory specificity training in adolescents (Pile et al.), as well as an intervention on rescripting painful memories in patients with social anxiety disorder (Romano et al.) are also included in this special issue. The effects of working memory training using non emotional stimuli (PASAT) in healthy older adults (Vanderhasselt et al.), high anxiety undergraduates (Van den Bergh et al.), remitted depressed patients (Vervaeke and colleagues) and currently depressed patients (Ferrari et al.) are investigated on various outcome measures. Also, the effect of a competitive memory training (COMET) on Attentional-Bias is investigated in Post-Traumatic Stress Disorder among cancer patients (Farahimanesh et al.). Moreover, objective and subjective indices of performance during a visual working memory task reveal mechanistic insights in depressed patients (Wood-Ross et al.). Somewhat relatedly, an emotional working memory training yields neurocognitive and worry symptoms improvement in high worrying individuals (Lofti et al.). To highlight the importance of neural functioning in memory training, the causal modulation of affective learning using tDCS of the prefrontal cortex has also been included in this special issue (Overman and colleagues 2020). By providing this up-to-date overview of the field of memory training, we hope to stimulate future integration of training- and treatment approaches, possibly resulting in optimized treatment outcomes for emotional disorders.

Acknowledgements The quote used in the title: "Memories Warm You Up from the Inside. But They also Tear You Apart" was taken from the novel 'Kafka on the Shore' by Haruki Murakami.

Conflicts of Inteest E. S. Becker, M.-A. Vanderhasselt, E. H. W. Koster and J. N. Vrijsen declare that they have no conflicts of interest.

Ethical approval All procedures performed in studies involving human participants were in accordance with the ethical standards of the institutional and/or national research committee and with the 1964 Helsinki declaration and its later amendments or comparable ethical standards.

Informed Consent Informed consent was obtained from all individual participants included in the studies presented in this special issue.

Research Involving Animal Rights No animal studies are included in this special issue.

\section{References}

Asarnow, L. D., Thompson, R. J., Joormann, J., \& Gotlib, I. H. (2014). Children at risk for depression: Memory biases, self-schemas, and genotypic variation. Journal of Affective Disorders, 159, 66-72.

Au, J., Sheehan, E., Tsai, N., Duncan, G. J., Buschkuehl, M., \& Jaeggi, S. M. (2015). Improving fluid intelligence with training on working memory: A meta-analysis. Psychonomic Bulletin \& Review, $22,366-377$.

Bartlett, F. C. (1932). Remembering: A study in experimental and social psychology. Cambridge University Press.

Beck, A. T. (1963). Thinking and depression: Idiosyncratic content and cognitive distortions. Archives of General Psychiatry, 9, 324-333. 
Beck, A. T. (1964). Thinking and depression: 2. Theory and therapy. Archives of General Psychiatry, 10, 561-571.

Becker, E., Rinck, M., \& Margraf, J. (1994). Memory bias in panic disorder. Journal of Abnormal Psychology, 103, 396-399.

Bower, G. H. (1981). Mood and memory. American Psychologist, 36(2), 129.

Bower, G. H. (1987). Commentary on mood and memory. Behaviour Research and Therapy, 25(6), 443-455.

Brewin, C. R. (2001). Memory processes in post-traumatic stress disorder. International Review of Psychiatry, 13(3), 159-163.

Brooks, S. J., Funk, S. G., Young, S. Y., \& Schiöth, H. B. (2017). The role of working memory for cognitive control in anorexia nervosa versus substance use disorder. Frontiers in Psychology, 8, 1651.

Brunet, A., Orr, S. P., Tremblay, J., Robertson, K., Nader, K., \& Pitman, R. K. (2008). Effect of post-retrieval propranolol on psychophysiologic responding during subsequent script-driven traumatic imagery in post-traumatic stress disorder. Journal of Psychiatric Research, 42(6), 503-506.

Coles, M. E., \& Heimberg, R. G. (2002). Memory biases in the anxiety disorders: Current status. Clinical Psychology Review, 22(4), $587-627$.

Ehlers, A., Hackmann, A., \& Michael, T. (2004). Intrusive re-experiencing in post-traumatic stress disorder: Phenomenology, theory, and therapy. Memory, 12(4), 403-415.

Elsey, J. W., \& Kindt, M. (2017). Tackling maladaptive memories through reconsolidation: From neural to clinical science. Neurobiology of Learning and Memory, 142, 108-117.

Everaert, J., Duyck, W., \& Koster, E. H. W. (2014). Attention, interpretation, and memory biases in subclinical depression: A proofof-principle test of the combined cognitive biases hypothesis. Emotion, 14(2), 331-340.

Freud, S. (1916/1917). Vorlesungen zur Einführung in die Psychoanalyse, Studienausgabe Band 1.

Goodman, J. B., Freeman, E. E., \& Chalmers, K. A. (2019). The relationship between early life stress and working memory in adulthood: A systematic review and meta-analysis. Memory, 27(6), 868-880.

Hertel, P. T. (1997). On the contribution of deficient cognitive control to memory impairments in depression. Cognition and Emotion, $11,569-584$

Hertel, P., Maydon, A., Cottle, J., \& Vrijsen, J. (2017). Cognitive bias modification: Retrieval practice to simulate and oppose ruminative memory biases. Clinical Psychological Science, 5, 122-130.

Holmes, E. A., Arntz, A., \& Smucker, M. R. (2007). Imagery rescripting in cognitive behaviour therapy: Images, treatment techniques and outcomes. Journal of Behavior Therapy and Experimental Psychiatry, 38(4), 297-305.

Isen, A. M. (1984). Toward understanding the role of affect in cognition. In R. S. Wyer \& T. S. Srull (Eds.), Handbook of social cognition (pp. 179-236). Erlbaum.

Jaeggi, S. M., Buschkuehl, M., Jonides, J., \& Perrig, W. J. (2008). Improving fluid intelligence with training on working memory. Proceedings of the National Academy of Sciences, 105(19), 6829-6833.

Joormann, J. (2005). Inhibition, rumination, and mood regulation in depression. In R. W. Engle, G. Sedek, U. von Hecker, \& D. N. McIntosh (Eds.), Cognitive limitations in aging and psychopathology: Attention, working memory, and executive functions (pp. 275-312). Cambridge University Press.

Joormann, J., \& Stanton, C. H. (2016). Examining emotion regulation in depression: A review and future directions. Behaviour Research and Therapy, 86, 35-49.

Joormann, J., Talbot, L., \& Gotlib, I. H. (2007). Biased processing of emotional information in girls at risk for depression. Journal of Abnormal Psychology, 116(1), 135.
Kindt, M., \& van Emmerik, A. (2016). New avenues for treating emotional memory disorders: Towards a reconsolidation intervention for posttraumatic stress disorder. Therapeutic Advances in Psychopharmacology, 6(4), 283-295.

Klingberg, T. (2010). Training and plasticity of working memory. Trends in Cognitive Sciences, 14(7), 317-324.

Korrelboom, K., de Jong, M., Huijbrechts, I., \& Daansen, P. (2009). Competitive memory training (COMET) for treating low selfesteem in patients with eating disorders: A randomized clinical trial. Journal of Consulting and Clinical Psychology, 77(5), 974.

Koster, E. H., De Lissnyder, E., Derakshan, N., \& De Raedt, R. (2011). Understanding depressive rumination from a cognitive science perspective: The impaired disengagement hypothesis. Clinical Psychology Review, 31(1), 138-145.

Koster, E. H. W., Hoorelbeke, K., Onraedt, T., Owens, M., \& Derakshan, N. (2017). Cognitive control interventions for depression: A systematic review of findings from training studies. Clinical Psychology Review, 53, 79-92.

Linville, P. (1996). Attention inhibition: Does it underlie ruminative thought? In R. S. Wyer (Ed.), Ruminative thoughts: Vol. 9. Advances in social cognition (pp. 121-133). Erlbaum.

Loftus, E. F. (1997). Creating false memories. Scientific American, 277(3), 70-75.

Loftus, E. F., \& Bernstein, D. M. (2005). Rich false memories: The royal road to success. In A. F. Healy (Ed.), Decade of behavior. Experimental cognitive psychology and its applications (pp. 101-113). American Psychological Association.

Mackinger, H. F., Loschin, G. G., \& Leibetseder, M. M. (2000). Prediction of postnatal affective changes by autobiographical memories. European Psychologist, 5(1), 52.

Matt, G. E., Vázquez, C., \& Campbell, W. K. (1992). Mood-congruent recall of affectively toned stimuli: A meta-analytic review. Clinical Psychology Review, 12(2), 227-255.

McDonald, R. J., Devan, B. D., \& Hong, N. S. (2004). Multiple memory systems: The power of interactions. Neurobiology of Learning and Memory, 82(3), 333-346.

Mitte, K. (2008). Memory bias for threatening information in anxiety and anxiety disorders: A meta-analytic review. Psychological Bulletin, 134, 886-911.

Morina, N., Lancee, J., \& Arntz, A. (2017). Imagery rescripting as a clinical intervention for aversive memories: A meta-analysis. Journal of Behavior Therapy and Experimental Psychiatry, 55, 6-15.

Overman, M. J., Browning, M., \& O'Shea, J. (2020). Inducing affective learning biases with cognitive training and prefrontal tDCS: A proof-of-concept study. Cognitive Therapy and Research. https:// doi.org/10.1007/s10608-020-10146-9

Phelps, E. A., \& Hofmann, S. G. (2019). Memory editing from science fiction to clinical practice. Nature, 572, 43-50.

Platt, B., Waters, A. M., Schulte-Koerne, G., Engelmann, L., \& Salemink, E. (2017). A review of cognitive biases in youth depression: Attention, interpretation and memory. Cognition and Emotion, 31(3), 462-483.

Quirk, G. J., Paré, D., Richardson, R., Herry, C., Monfils, M. H., Schiller, D., \& Vicentic, A. (2010). Erasing fear memories with extinction training. Journal of Neuroscience, 30(45), 14993-14997.

Schouten, D. I., Pereira, S. I., Tops, M., \& Louzada, F. M. (2017). State of the art on targeted memory reactivation: Sleep your way to enhanced cognition. Sleep Medicine Reviews, 32, 123-131.

Shipstead, Z., Redick, T. S., \& Engle, R. W. (2012). Is working memory training effective? Psychological Bulletin, 138, 628-654.

Siegle, G. J., Ghinassi, Æ. F., \& Thase, Æ. M. E. (2007). Neurobehavioral therapies in the 21 st century: Summary of an emerging field and an extended example of cognitive control training for depression. Cognitive Therapy and Research, 31, 235-262. 
Simons, D. J., Boot, W. R., Charness, N., Gathercole, S. E., Chabris, C. F., Hambrick, D. Z., \& Stine-Morrow, E. A. L. (2016). Do "braintraining" programs work? Psychological Science in the Public Interest, 17(3), 103-186.

Stocks, J. T. (1998). Recovered memory therapy: A dubious practice technique. Social Work, 43(5), 423-436.

Vanderhasselt, M.-A., De Raedt, R., Brunoni, A. R., Campanhã, C., Baeken, C., Remue, J., \& Boggio, P. S. (2013). tDCS over the left prefrontal cortex enhances cognitive control for positive affective stimuli. PLoS ONE, 8(5), e62219.

Visser, D. A., Tendolkar, I., Schene, A. H., van de Kraats, L., Ruhe, H. G., \& Vrijsen, J. N. (2020). A pilot study of smartphonebased memory bias modification and its effect on memory bias and depressive symptoms in an unselected population. Cognitive Therapy and Research, 44, 61-72.

Vrijsen, J. N., Dainer-Best, J., Witcraft, S. M., Papini, S., Hertel, P., Beevers, C. G., et al. (2019). Effect of cognitive bias modificationmemory on depressive symptoms and autobiographical memory bias: Two independent studies in high-ruminating and dysphoric samples. Cognition \& Emotion, 33, 288-304.

Vrijsen, J. N., Hertel, P. T., \& Becker, E. S. (2016). Practicing emotionally biased retrieval affects mood and establishes biased recall a week later. Cognitive Therapy and Research, 40, 764-773.
Williams, J. M. G., Barnhofer, T., Crane, C., Herman, D., Raes, F., Watkins, E., \& Dalgleish, T. (2007). Autobiographical memory specificity and emotional disorder. Psychological Bulletin, 133(1), 122-148.

Wood, N. E., Rosasco, M. L., Suris, A. M., Spring, J. D., Marin, M. F., Lasko, N. B., et al. (2015). Pharmacological blockade of memory reconsolidation in posttraumatic stress disorder: Three negative psychophysiological studies. Psychiatry Research, 225(1-2), 31-39.

Young, J. E., Klosko, J. S., \& Weishaar, M. E. (2003). Schema therapy (p. 254). Guilford.

Zetsche, U., Bürkner, P. C., \& Schulze, L. (2018). Shedding light on the association between repetitive negative thinking and deficits in cognitive control-A meta-analysis. Clinical Psychology Review, $63,56-65$.

Publisher's Note Springer Nature remains neutral with regard to jurisdictional claims in published maps and institutional affiliations. 